\title{
UNA CARTOGRAFÍA PARA EL PRINCIPIO DE IGUALDAD EN CHILE. ANÁLISIS DE LA PRODUCTIVIDAD DOGMÁTICA ENTRE 2000 Y 2018*
}

A cartography for the principle of equality in Chile. Analysis of doctrine productivity between 2000 and 2018

\author{
LUIS VILLAVICENCIO MIRANDA** \\ Universidad de Valparaíso \\ SOLEDAD FERNÁNDEZ BERNAL *** \\ Universidad de Valparaíso \\ CLAUdio AgüERo SAN JUAN $* * * *$ \\ Universidad Alberto Hurtado \\ RODOLFO FIGUEROA GARCíA-HUIDOBRO***** \\ Universidad Diego Portales \\ YANIRA ZÚÑIGA AÑAZCO ****** \\ Universidad Austral de Chile \\ MARÍA BEATRIZ ARRIAGADA CÁCERES $* * * * * * *$ \\ Universidad Diego Portales
}

\begin{abstract}
RESUMEN
El trabajo realiza una cartografía de la producción académica chilena relativa al principio de igualdad, enfocada en los autores y sus artículos. Respecto de los autores, ellos se ordenan en torno a ocho criterios: el número y género de autores; distribución de textos por autores; distribución de productividad en el tiempo; distribución y concentración de artículos por revistas; adscripción institucional de los autores; temáticas recurrentes; autores más citados en los artículos, y uso de la jurisprudencia en los artículos de revistas. En cuanto a los artículos elaborados por esos autores y sus temáticas, este texto esboza dos hipótesis para explicar esa producción académica.
\end{abstract}

\section{PALABRAs Clave}

Igualdad, Derechos Fundamentales, dogmática.

\footnotetext{
* Este artículo ha sido posible gracias al Proyecto FONDECYT Regular № 1180676. Las autoras y los autores de este texto constituyen el grupo de trabajo del proyecto individualizado, formado por el investigador responsable, los coinvestigadores y la ayudante de investigación. Todos ellos han intervenido en la confección, revisión y validación del corpus y de la muestra, como así mismo en la preparación del presente manuscrito. Sus conclusiones han sido consensuadas por todo el equipo.

** Doctor en Derecho, Universidad Autónoma de Madrid. Director del Centro de Investigaciones de Filosofía del Derecho y Derecho Penal, Universidad de Valparaíso, Valparaíso, Chile. Correo electrónico: luis.villavicencio@uv.cl.

*** Profesora de la Facultad de Derecho de la Universidad de Valparaíso, Valparaíso, Chile. Correo electrónico: soledad.fernandez@uv.cl.

**** Doctor en Ciencias Humanas, Universidad Austral de Chile. Profesor de la Facultad de Derecho de la Universidad Alberto Hurtado, Santiago, Chile. Correo electrónico: aguero.claudio@gmail.com.

***** Doctor en Derecho, Universidad de Wisconsin (EE. UU). Profesor de la Facultad de Derecho de la Universidad Diego Portales, Santiago, Chile. Correo electrónico: rodolfo.figueroa@udp.cl.

****** Doctora en Derecho, Universidad Carlos III de Madrid, España. Profesora de la Facultad de Derecho de la Universidad Austral de Chile, Valdivia, Chile. Correo electrónico: yzuniga@uach.cl.

${ }_{* * * * * * *}$ Doctora en Derecho, Universidad de Chile. Profesora e investigadora de la Facultad de Derecho de la Universidad Diego Portales, Santiago, Chile. Correo electrónico: mbeatriz.arriagada@gmail.com.
} 


\section{ABSTRACT}

This paper offers a cartography of the Chilean scholarly production regarding the Principle of Equality, focused both on their authors and their work. Regarding the authors, the information is organized according to eight criteria: number and gender; distribution of papers by author; distribution of productivity along time; distribution of papers based on the journals where they were published; the authors institutional affiliation; recurrent themes; the most cited authors; and the use of jurisprudence. Regarding the kind of work produced by such authors and their themes, this paper offers two hypotheses to explain them.

\section{KEYWORDS}

Equality, Fundamental Rights, doctrine.

\section{Introducción}

Este artículo es parte de un proyecto FONDECYT que analiza la doctrina y jurisprudencia recaída sobre el principio de igualdad desde el año 2000 al 2018 ${ }^{1}$. Ese análisis será multidisciplinario y multidimensional. Una primera parte de ese proyecto consiste en cartografiar la producción académica chilena sobre igualdad: quiénes han escrito y las temáticas y enfoques de igualdad que han escogido, sin entrar todavía al análisis de contenido cada artículo. Además, se esbozan dos hipótesis sobre esa productividad. Eso es lo que muestra el presente texto. El análisis de contenido de la doctrina y jurisprudencia será objeto de otros artículos conectados entre sí, emanados de este proyecto².

Para cumplir el propósito del presente trabajo, utilizamos seis criterios o filtros: a) el período temporal; b) la nacionalidad de los autores; $c$ ) el género discursivo de los textos; d) un listado de palabras claves; e) el enfoque disciplinar de los textos; y f) el contenido. Por su parte, fijamos ocho patrones de comparación: a) el número y género de la doctrina; b) la concentración de los trabajos por persona; c) la distribución de los trabajos en el tiempo; d) la distribución y concentración de artículos en revistas; e) la adscripción o afiliación institucional de los autores; f) la agrupación de artículos de revistas por temáticas más recurrentes; g) los autores más citados en los artículos de revistas; y h) el uso de jurisprudencia en los artículos de revistas. Estos criterios fueron construidos a partir del trabajo con el mismo corpus usando una metodología de teoría fundamentada o Grounded Theory ${ }^{3}$.

El trabajo tiene dos partes bien definidas. En la primera parte, exponemos la metodología utilizada para definir el corpus y, luego, presentamos la muestra considerando los criterios y los parámetros de comparación ya indicados (apartados II y III). En la segunda parte (apartado IV), adelantamos algunas hipótesis exploratorias que consideramos relevantes y que esperamos profundizar en trabajos futuros. Estas conjeturas fluyen del examen panorámico de las temáticas sobre las que versan los trabajos que componen la muestra y plantean, fundamentalmente, que es posible identificar dos momentos de producción científica en torno al principio de igualdad, conectados con la agenda legislativa y el debate público. Finalmente, el trabajo se cierra con una lista de conclusiones (apartado V).

\section{Metodología}

\subsection{Fuentes y búsqueda}

Las fuentes bibliográficas consultadas fueron revistas académicas e institucionales, tanto universitarias como de organismos públicos y privados, de acceso abierto o pagadas, disponibles

\footnotetext{
${ }^{1}$ Puede revisarse el modo en que comprendemos el principio de igualdad en VILLAVICENCIO (2018), pp. 43-74.

${ }^{2}$ En próximos trabajos exploraremos los temas más recurrentes que ha examinado la doctrina. Luego esperamos conectar ese examen con la jurisprudencia sobre igualdad en el mismo período (la investigación contempla también un corpus de fallos). Finalmente, pretendemos que esa doble sistematización nos permita, desde un punto de vista metajurisprudencial y metadogmático, contribuir a una comprensión más fina del principio de igualdad.

${ }^{3}$ GLASSER (1992) y STRAUSS Y CORBIN (1998).
} 
virtualmente o en formato físico, sin restricciones de idioma ${ }^{4}$ y editadas en Chile. La lista total de fuentes analizadas corresponde a 50 revistas, revisándose 1010 números, correspondientes al cien por ciento de los volúmenes editados entre los años 2000 y 2018. La revisión final fue realizada a mediados de 2019, por lo que se incluyeron volúmenes que, hasta esa fecha, estaban disponibles en catálogos en línea tales como Vlex, SciELO, SCOPUS y WOS.

La búsqueda contempló tres etapas de revisión que operaron de forma iterativa y no secuencial. Éstas permitieron hacer más exhaustiva la exploración bibliográfica hasta saturarla y así evitar cualquier omisión. A su vez, en cada etapa se aplicaron seis filtros o criterios de selección para construir la muestra final. La primera etapa consistió en un barrido por los índices de todas las revistas consultadas, a través de palabras claves asociadas al contenido de los artículos. Esta revisión fue tanto presencial como en plataformas virtuales - dependiendo de la disponibilidad de la revista en Internet- rastreándose las palabras claves, los títulos y los resúmenes de los artículos publicados.

En la segunda etapa se confeccionó una lista con los autores y las autoras de todos los artículos. Esta lista fue utilizada para confeccionar una trayectoria de productividad del autor, contrastando sus temáticas y materias de interés. Ello nos permitió incorporar más textos a la muestra al indagar, por ejemplo, en publicaciones de revistas extranjeras o libros y capítulos de libros que no estaban considerados en la muestra inicial. Sin embargo, para efectos del análisis que se presenta en este trabajo, solo mantuvimos los trabajos publicados en revistas, pues solo respecto de ellos la búsqueda pudo ser totalmente exhaustiva.

En la tercera y última etapa se examinó someramente la muestra. Esta lectura se realizó con el propósito de fijar vínculos intertextuales y comparar las bibliografías utilizadas.

\subsection{Criterios}

Los criterios de selección se aplicaron a la muestra en cada una de las tres etapas. Estas etapas fueron realizadas de modo iterativo y no de forma lineal. La finalidad fue limitar el corpus a los artículos, los libros y los capítulos de libros de la doctrina nacional que reflexionan en torno al principio de igualdad desde una perspectiva jurídica en sentido amplio ${ }^{5}$. Con esta expresión nos referimos a todo trabajo que se ocupe de la igualdad aplicando los métodos que los juristas suelen utilizar para ocuparse de problemas jurídicos: a) la identificación y sistematización del derecho vigente; b) la construcción de concepciones jurídicas generales o específicas; c) la formulación de una respuesta a algún problema interpretativo ya sea doctrinal o jurisprudencial; y d) la reflexión sobre la justicia de normas positivas o teorías jurídicas ${ }^{6}$.

El primer criterio fue temporal. La búsqueda comprendió los años 2000 a 2018, ambos inclusive. Conforme a este criterio se admitieron como piezas del corpus analizado todos los artículos, los capítulos de libros y los libros publicados en esos años.

El segundo criterio fue la nacionalidad de quien firma como autor o autora. Se seleccionaron solo firmas chilenas, incluyendo textos en coautoría con extranjeros. Ahora bien, por aplicación de otros criterios estos últimos textos resultaron excluidos. Así, la lista de firmas computa a personas, mientras que la lista de autores computa las veces que una persona figura como el responsable de un texto. Aquí no hicimos ninguna distinción entre obras de único autor o de autores colectivos.

Para efectos de acotar aún más la lista, se excluyeron coautores extranjeros en obras conjuntas con autores nacionales.

El tercer criterio fue el género discursivo de los textos. Admitimos tres géneros: libros, capítulos de libros y artículos científicos. Así fueron excluidos otros géneros tales como

\footnotetext{
${ }^{4}$ Aunque no introdujimos restricciones idiomáticas en la búsqueda, finalmente la totalidad de los trabajos revisados fueron escritos en lengua castellana.

${ }^{5}$ La expresión corpus la usamos como recopilación ordenada de muestras homogéneas de lenguaje. Mientras que muestra significa un espécimen o fragmento del corpus. Seguimos en este punto TORRUELLA Y LLISTERRI (1999) pp. 45-46.

${ }^{6}$ CRUZ (2006), pp. 17-39.
} 
recensiones, tesis, tesinas, memorias, columnas de opinión, etcétera. No se realizó ninguna distinción sobre la casa editorial, más allá de que fuese una publicación chilena.

El cuarto criterio fue el uso de un listado de palabras que debían aparecer en el título o en el resumen de las publicaciones. Los términos buscados fueron: igualdad, equidad, discriminación, acción afirmativa, categorías sospechosas, inclusión y exclusión, políticas de reconocimiento y justicia distributiva.

El quinto criterio fue el enfoque disciplinar de los textos. Se seleccionaron textos cuyo tratamiento de la igualdad fuese normativo, conforme al enfoque jurídico amplio definido antes. Esto implicó dejar de lado los textos con orientaciones o metodologías diversas.

El sexto criterio está determinado por el contenido de los textos. Así fueron seleccionados solo aquellos que desarrollaran alguna dimensión del principio de igualdad. Específicamente, incluimos trabajos que identifiquen, describan o sistematicen reglas constitucionales o legales vinculadas al principio de igualdad. También consideramos textos que elaboran una concepción del principio de igualdad, ya sea inductivamente a partir de las reglas del sistema, o deductivamente a partir de una cierta teoría de la justicia. Por otro lado, incluimos trabajos que argumentan a favor de alguna solución, anclada en el principio de igualdad ${ }^{7}$, para un problema interpretativo doctrinal o jurisprudencial. Finalmente, incorporamos trabajos que se ocupen, conceptual o dogmáticamente, de uno o más conceptos vinculados al principio de igualdad.

El uso de estos seis criterios arrojó un corpus de 235 artículos, 17 capítulos de libros y 25 libros. Asimismo, la aplicación de estos criterios nos permitió configurar un corpus textual que considera los principios para la conformación de colecciones ecológicas, esto es: integridad y claridad sobre la procedencia (Parodi, 2010), reputación (Nwogu,1997) y accesibilidad (Flores, 2009). Del corpus se extrajo la muestra finalmente analizada, a la cual se aplicaron cada una de las variables que siguen. Dicha muestra se compone de 235 artículos, para efectos de asegurar la exhaustividad y control de la base doctrinal ${ }^{8}$.

\subsection{Definición de las variables de comparación}

Las variables utilizadas son ocho. En primer lugar, consideramos el número y género de la doctrina. Hemos contabilizado a cada persona chilena que haya escrito un artículo sobre la igualdad desde una perspectiva jurídica amplia, distinguiendo a la persona individual representada por su firma, por una parte, del número de autores/as de cada trabajo, por otra. También hemos registrado el género de los autores, diferenciando entre mujeres y hombres ${ }^{9}$.

En segundo lugar, hemos considerado la concentración de los trabajos por persona, esto es, identificar cuáles son los autores que más artículos han escrito en Chile sobre el principio de igualdad desde una perspectiva jurídica amplia.

En tercer lugar, hemos distribuidos los trabajos en el tiempo, considerando el año de publicación de cada artículo.

En cuarto lugar, indicamos la distribución y concentración de artículos en las revistas.

En quinto lugar, clasificamos la adscripción o afiliación institucional de los autores, según la información contenida en los propios trabajos. En los casos de más de una adscripción se ha considerado la primera declarada.

En sexto lugar, hemos agrupado los artículos de revistas según las temáticas más recurrentes. Para identificar tales temáticas hemos revisado el título, subtítulo si corresponde,

\footnotetext{
${ }^{7}$ Varios tópicos asociados al principio de igualdad fueron excluidos por contener solo referencias tangenciales. Así, por ejemplo, algunos artículos sobre exigibilidad de los derechos se incorporaron a la muestra si la argumentación se entroncaba con el principio de igualdad, restando aquellas obras que solo lo mencionaran.

8 Seleccionamos solo artículos porque cuidamos que la muestra fuese homogénea. Naturalmente, esta decisión implica una investigación menos representativa del conjunto de textos jurídicos pues deja de lado los libros y los capítulos de libros. A pesar de ese costo, pensamos que la investigación sigue siendo relevante en la medida que los mecanismos de financiamiento de la ciencia en Chile, progresivamente han fortalecido los incentivos para que los investigadores publiquen artículos en lugar que otros tipos de textos.

${ }^{9}$ No ha sido necesario ninguna distinción adicional pues no se registraron autores que se identifiquen con otros géneros.
} 
palabras claves y resúmenes de los trabajos. En aquellos casos en el que los textos no contenían resúmenes se han leído sus introducciones para efectos de su clasificación.

En séptimo lugar, hemos identificado cuáles son los autores más citados en los artículos de revistas que constituyen la muestra, distinguiendo entre autores chilenos y extranjeros.

Finalmente, hemos verificado si los artículos de revistas usan jurisprudencia en sus análisis. Se registraron tanto los casos en que los autores examinan o hacen referencias a fallos. No se distinguieron tipos de resoluciones o clases de tribunales.

\section{Resultados del análisis de la muestra}

El análisis es descriptivo pues intentamos hacer un resumen cuantitativo de los datos que hemos recogido. De esta manera, solo describimos una tendencia en los procesos de publicación de los juristas chilenos estudiados en un periodo de tiempo y, entonces, es necesario advertir que las afirmaciones que realizamos en este apartado son difícilmente generalizables a toda la comunidad jurídica chilena (García y Agüero, 2014) ${ }^{10}$. Por esta razón, al final de este artículo usamos la expresión hipótesis para calificar nuestras observaciones.

\subsection{El número y género de la doctrina}

a) Número de firmas y de autores y autoras de la muestra completa. La muestra expresa el trabajo de 157 firmas, es decir, individuos. Esas firmas se convierten en 189 autores y autoras.

b) Representación por género de las firmas

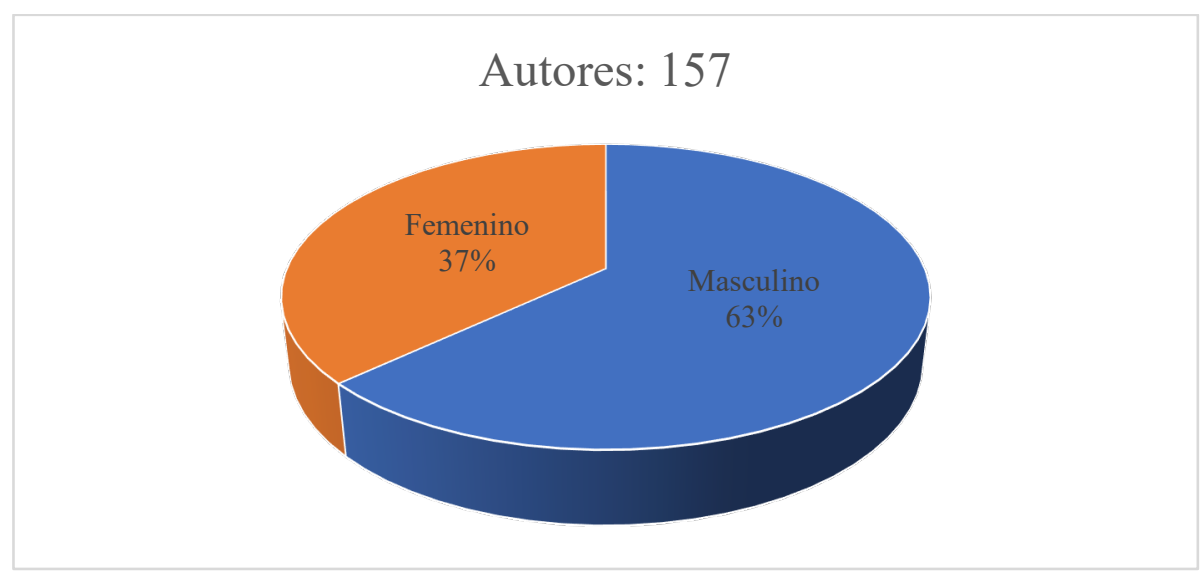

En cuanto al género, reconocemos que, de las 157 firmas, 58 (37\%) usan nombres atribuibles a mujeres y 99 usan nombres atribuibles a hombres (63\%). Luego, podríamos estimar que la muestra se acerca al equilibrio de género, pero sin llegar a ser paritario ${ }^{11}$.

\footnotetext{
${ }^{10}$ Usamos los conceptos de comunidad jurídica y comunidad normativa en el sentido de GARCÍA Y AGÜERO (2014).

${ }^{11}$ Entendemos por equilibro de género un porcentaje que refleje una distribución aceptable entre los géneros, sin que la diferencia pueda atribuirse a barreras estructurales o a alguna clase de discriminación subyacente, sino a una legítima diversidad de intereses o méritos. En cambio, la paridad supone que, dado que los géneros se distribuyen porcentualmente de forma casi igual, debería esperarse una distribución también igual.
} 


\subsection{La concentración de trabajos por persona}

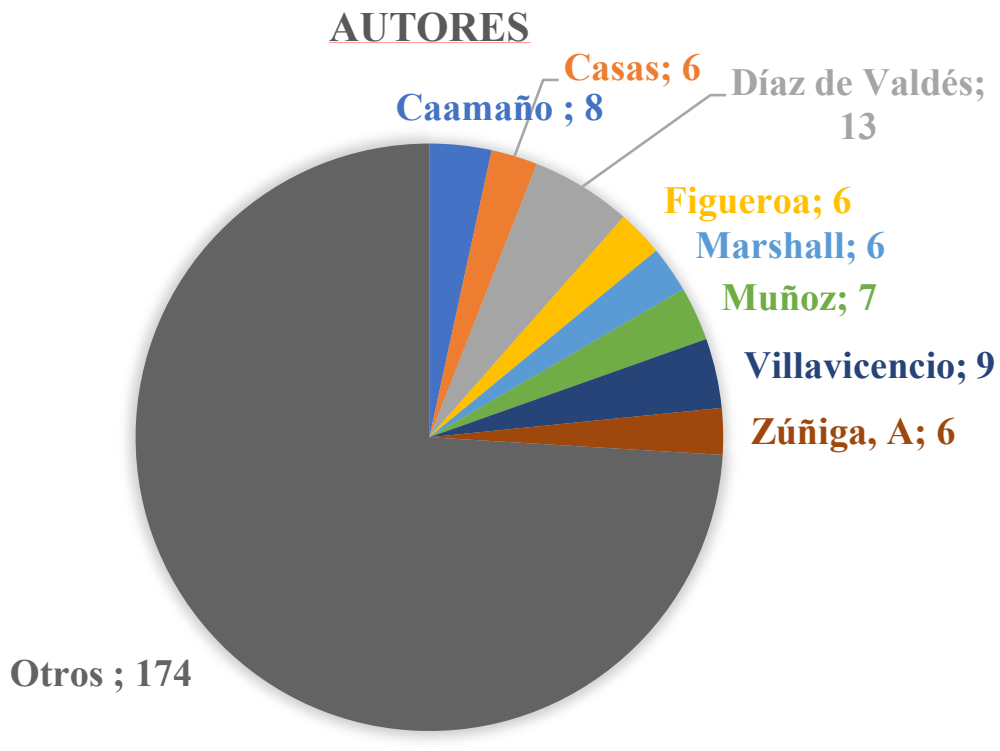

En lo relativo a la cantidad de publicaciones por persona o firma, hay un porcentaje mayoritario de dispersión de publicaciones de artículos $(72,2 \%)$, considerando el total de académicos que figuran con una sola publicación. Sin embargo, por otro lado, hay una concentración relevante de trabajos en un puñado de personas. Así, 8 firmas (correspondiente al $5,09 \%$ ) concentra un cuarto de las publicaciones $(25,9 \%)$. Los académicos que concentran la producción son los siguientes:

- $\quad$ José Manuel Díaz de Valdés con 13 textos.

- $\quad$ Luis Villavicencio con 9 textos.

- $\quad$ Fernando Muñoz con 7 textos.

- $\quad$ Eduardo Caamaño con 6 textos.

- $\quad$ Lidia Casas, Rodolfo Figueroa, Pablo Marshall y Alejandra Zúñiga con 6 textos.

\subsection{Distribución de los trabajos en el tiempo}

Las publicaciones anuales que desarrollan el principio de igualdad se han incrementado en los últimos diez años si se compara la primera década de este siglo con la segunda. 


\section{CLASIFICACIÓN POR AÑO: PUBLICACIONES}

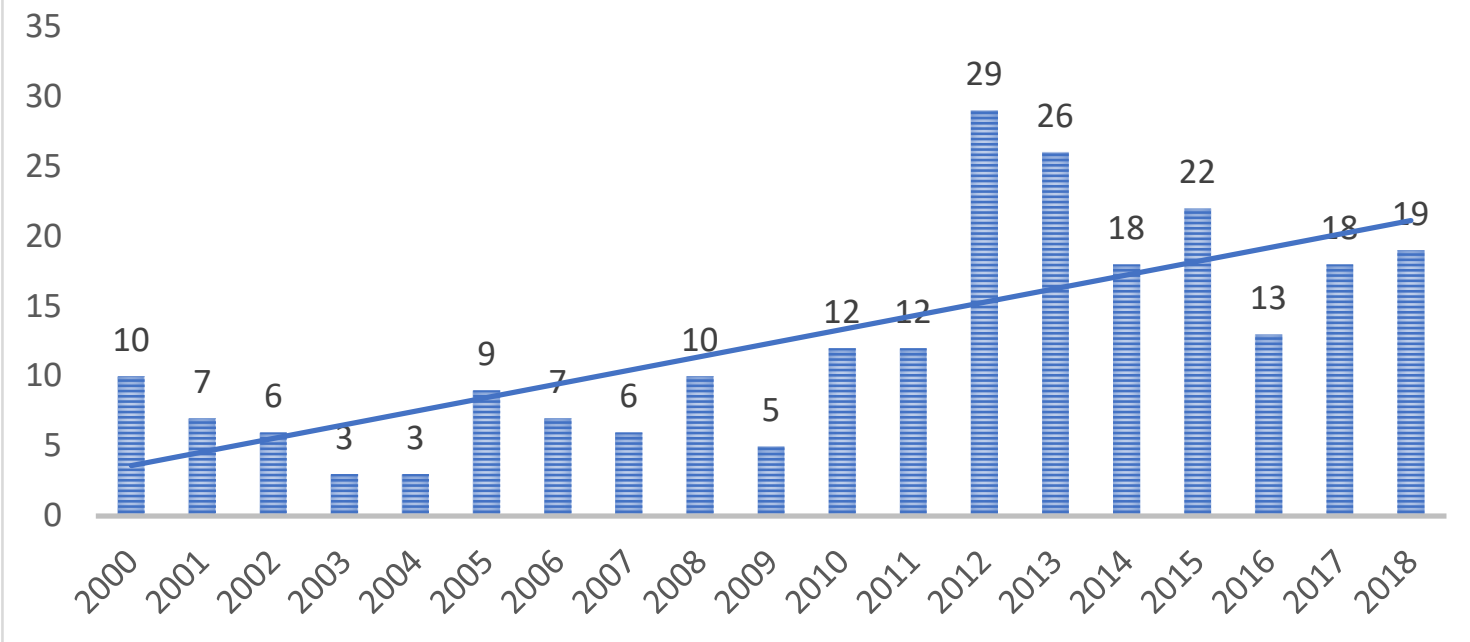

El gráfico muestra que la productividad académica está determinada, en parte, por la creación legislativa y el debate público en torno a problemas sociales sobre la igualdad. Aunque fundar por completo esta afirmación debe contrastar la productividad sobre la igualdad con otras áreas del derecho constitucional, podemos construir dos hipótesis sobre el propósito perseguido por los dogmáticos. La primera hipótesis afirma que los juristas producen según los dictados de la creación legislativa con un propósito colegislador. La productividad, entonces, estaría orientada a ejercer influencia en el trabajo legislativo. El problema de esta hipótesis es claro: muchos trabajos dogmáticos no son acogidos directamente por el legislador y/o se publican después que el trabajo del legislador ha concluido. Una segunda hipótesis afirma que los juristas producen sus trabajos en sintonía con el legislador porque buscan influir en los jueces cuando deban resolver casos con la nueva legislación. El problema de esta hipótesis es que las sentencias nacionales son lacónicas y pocas de ellas citan explícitamente la dogmática que usan para argumentar las sentencias que dictan. Una tercera hipótesis afirma que los juristas producen sus trabajos en sintonía con el legislador debido a que los litigantes necesitan respuestas frente a la incertidumbre que genera el cambio legislativo. El problema de esta hipótesis es que los registros de los litigantes y las citas de la dogmática en los escritos judiciales son difíciles de pesquisar. Así, solo es posible estudiar los casos en donde los juristas intervienen con informes en derecho o como amicus curiae. No es trivial señalar que estas tres hipótesis son minimalistas y pueden combinarse en hipótesis más productivas, debido a la dinámica de la comunidad jurídica nacional a través de la multiplicidad de roles que un abogado puede cumplir en el ejercicio de su profesión.

\subsection{Distribución y concentración de los artículos en revistas}

La muestra se compone de 50 revistas. De ellas, 11 concentran el 63,4\% (149 textos). El detalle de este cálculo se encuentra en el siguiente recuadro: 


\begin{tabular}{|l|c|c|c|}
\hline \multicolumn{1}{|c|}{ Revista } & Institución & $\begin{array}{c}\text { Número artículos } \\
\text { en revistas }\end{array}$ & $\%$ \\
\hline Anuario de Derecho Público & U. Diego Portales & 21 & 9 \\
\hline Revista de Derecho (Valdivia) & U. Austral de Chile & 20 & 8,5 \\
\hline Revista de Actualidad Jurídica & U. del Desarrollo & 18 & 7,6 \\
\hline Revista Chilena de Derecho & P. U. Católica de Chile & 15 & 6,3 \\
\hline Revista de Derecho (Valparaíso) & $\begin{array}{c}\text { P. U. Católica de } \\
\text { Valparaíso }\end{array}$ & 15 & 6,3 \\
\hline Derecho y Humanidades & U. de Chile & 13 & 5,5 \\
\hline Revista de Derecho (Coquimbo) & U. Católica del Norte & 12 & 5,1 \\
\hline Estudios Constitucionales & U. de Talca & 10 & 4,2 \\
\hline Anuario de Derechos Humanos & U. de Chile & 9 & 3,8 \\
\hline lus et Praxis & U. de Talca & 8 & 3,4 \\
\hline Revista de Ciencias Sociales & U. de Valparaíso & 8 & 3,4 \\
\hline Otras revistas & Varias & 86 & 36,6 \\
\hline Total & & 235 & 100,0 \\
\hline
\end{tabular}

Es evidente que, en materia de igualdad, dichas revistas agrupan la gran mayoría de las publicaciones. A su vez, dichas revistas se encuentran asociadas a las universidades que lideran la investigación científica en Chile ${ }^{12}$. De estas 11 revistas debemos destacar que todas son indexadas, abiertas y arbitradas, salvo el Anuario de Derecho Público de la Universidad Diego Portales y la Revista Actualidad Jurídica de la Universidad del Desarrollo que escogen autores por invitación.

\subsection{Autores según su adscripción o afiliación institucional}

Asociamos, ahora, los autores con las instituciones donde imparten docencia o trabajan. Aquellos casos en que verificamos que los autores no impartían docencia o no trabajaban en alguna institución conocida, los asociamos a la universidad en la que cursaron sus estudios de pregrado. Preferimos utilizar la afiliación voluntaria de los autores, la gran mayoría de las veces declarada en la propia publicación.

Como pudimos anticipar, los autores provenían mayoritariamente de las universidades listadas en el punto 3.4, siendo las más relevantes las que siguen. El corte se estableció en cinco firmas, considerando la dispersión de autores bajo ese número:

\begin{tabular}{|l|c|}
\hline \multicolumn{1}{|c|}{ Universidad } & Número de firmas \\
\hline Universidad de Chile & 30 \\
\hline Universidad Diego Portales & 17 \\
\hline Pontifica Universidad Católica de Chile & 12 \\
\hline Universidad de Valparaíso & 12 \\
\hline Universidad de Los Andes & 9 \\
\hline Universidad del Desarrollo & 8 \\
\hline Pontificia Universidad Católica de Valparaíso & 7 \\
\hline Universidad de Talca & 6 \\
\hline Universidad Austral de Chile & 6 \\
\hline Universidad Católica de Temuco & 6 \\
\hline Universidad Alberto Hurtado & 5 \\
\hline Otras instituciones & 71 \\
\hline Total & 189 \\
\hline
\end{tabular}

12 Así lo avalan estudios que miden la investigación científica de las universidades, tales como el Ranking SCImago (https://www.scimagoir.com/rankings.php?country=CHL) y el aS World University Ranking (https://www.topuniversities.com/university-rankings/world-university-rankings/2021). 
La tabla nos muestra que, de las 157 personas, 118 están vinculados a 11 universidades del país. Es decir, de 11 universidades nacionales proviene el $75 \%$ de autores que investigan sobre el principio de igualdad en Chile ${ }^{13}$. El protagonismo, tanto en producción de investigación científica, como en docentes que escriben en torno al principio de igualdad, suelen provenir de este mismo grupo de universidades.

Aunque las publicaciones de universidades ubicadas en Santiago constituyen el $51 \%$ de la muestra, existen focos de producción académica regionales, destacando la Universidad Católica del Norte en la región de Coquimbo, la Universidad de Valparaíso y Pontificia Universidad Católica de Valparaíso en la región de Valparaíso, la Universidad de Talca en la región del Maule y la Universidad Austral de Chile en la región de Los Ríos. Por debajo de la lista, igualmente mencionamos que, en la región del Biobío, la Universidad de Concepción cuenta con 4 autores, mientras que, en la región de Coquimbo, la Universidad Católica del Norte también cuenta con otros 4 autores.

En cuanto a las instituciones, hay un puñado de personas que publican desde sus puestos de trabajo en diversas instituciones. Destacan en la lista, autores que se desempeñan en el Instituto Nacional de Derechos Humanos, en el Ministerio Público, en la Defensoría Penal Pública y en el Poder Judicial. El total de trabajos asociados a otras instituciones alcanza el 12,1\%.

\subsection{Agrupación de artículos de revistas por temáticas más recurrentes}

Del examen de la muestra podemos distinguir dos momentos relevantes: uno desde el año 2000 al año 2009 y otro desde el año 2010 a la fecha. Adelantamos que, con la discusión de la ley Antidiscriminación, se dio paso a la configuración de un nuevo modelo conceptual del principio de igualdad y a la incorporación de nuevos problemas que suscitaron el interés de la doctrina.

A grandes rasgos, durante el primer período las temáticas se centraron en la igualdad como principio constitucional, mayormente desarrollado como derecho de igualdad ante la ley y derecho a no ser discriminado arbitrariamente. Algunos enfoques más específicos se dieron en materia laboral, con la discriminación y acoso laboral; en derecho de familia con cuestionamientos a la sociedad conyugal; y en derecho tributario, destacando el principio de igualdad tributaria.

El énfasis de las temáticas en el primer período alude, en general, a conceptos revisitados por la doctrina durante el segundo período. Así, a inicios del milenio, la discriminación arbitraria e igualdad formal son un centro de interés relevante para los autores, quienes discuten sobre igualdad constitucional e igualdad ante la ley, principalmente ante la potestad jurisdiccional ${ }^{14}$. Gran parte de la discusión doctrinaria tiene como planteamiento central la prohibición de discriminaciones arbitrarias bajo el alero del principio de igualdad en su aspecto formal ${ }^{15}$. Con todo, autoras como María Soledad Cisternas, ya adelantan la necesidad de contar con una ley antidiscriminación en el año $2004^{16}$, cuya discusión parlamentaria se inicia en 2005.

Junto con el aumento de artículos publicados, los que casi se triplican, se produce un giro notable en las temáticas durante el segundo período, ampliándose a nuevas áreas de interés doctrinal. Así, de 66 artículos académicos publicados entre 2000 y 2009, aumentan a 167 artículos en el segundo período entre 2010 y 2018. Nos parece necesario, a continuación, desglosar algunas de estas temáticas.

\footnotetext{
${ }^{13}$ Si consideramos el ranking SCImago 2020 (véase nota anterior), circunscribiéndola solo a las universidades chilenas que tienen facultades de derecho y que se encuentran entre las 10 primeras instituciones de ese listado, quedan fuera la Universidad de Concepción, Mayor y Andrés Bello.

${ }^{14}$ ATRIA (2000), pp. 103-112.

${ }^{15}$ ROJAS (2001), pp. 199-208.

${ }^{16}$ CISTERNAS (2003), pp. 409-437.
} 
La perspectiva de género ${ }^{17}$ tiene un alcance transversal en una importante cantidad de publicaciones. Muchos autores y autoras han ido incorporándola paulatinamente en sus investigaciones. Al hablar desde una perspectiva de género no solo discuten sobre discriminación, sino que también sobre ciudadanía, participación política, estereotipos y roles ${ }^{18}$. En cuanto al sistema electoral, se fundamentan - y en ocasiones se reprochan- las cuotas de género en el parlamento ${ }^{19}$ y en los sindicatos. En materia de derecho de familia, se critica la sociedad conyuga ${ }^{20}$ y las normas sobre filiación y cuidado personal ${ }^{21}$; mientras que, a propósito de pueblos indígenas e infancia, se empieza a hablar de discriminación múltiple o interseccionalidad ${ }^{22}$.

También resaltamos el interés de la doctrina por el análisis jurisprudencial del Tribunal Constitucional. Gran parte de este análisis corresponde a discusiones sobre matrimonio homosexual, educación y, en general, la noción de igualdad constitucional que defiende el máximo intérprete de la Constitución ${ }^{23}$.

Por otra parte, la temática vinculada a las disidencias sexuales abarca una serie de temas que estuvieron en boga a principios de la década. El caso Átala, el matrimonio homosexual y la identidad de género abarcaron varias publicaciones. El análisis de la ley antidiscriminación, de igual manera, se centra mayormente en la discriminación por orientación sexual ${ }^{24}$.

En una línea paralela, el derecho laboral sigue desarrollando temas similares, sin mayores cambios entre la primera y segunda década, basados en la discriminación de género ${ }^{25}$, maternidad y trabajo ${ }^{26}$, en la igualdad de remuneraciones y en la tutela de derechos fundamentales ${ }^{27}$.

Por último, los derechos sociales, principalmente la educación y la salud, agrupan una serie de publicaciones que remarcan el vuelco doctrinario, tras la irrupción del movimiento estudiantil, y cuyas mayores proyecciones se tradujeron en la demanda de exigibilidad de los derechos sociales al Estado ${ }^{28}$.

\subsection{Autores más citados en los artículos de revistas}

Con esta séptima variable nos preguntamos qué doctrina fue citada predominantemente. Para construir los cuadros con los autores más citados, hemos utilizado un doble criterio. En primer lugar, escogimos 5 autores internacionales y 6 nacionales porque los siguientes en la lista tienen, aproximadamente, la mitad de las citas del último elegido. En segundo lugar, hemos considerado el impacto de los autores citados, descartando aquellos que suman menos del $10 \%$ del total de trabajos.

a) Doctrina internacional

Al analizar la muestra, observamos que hay una tendencia bastante clara: según la tabla, cinco autores son los más citados. En la segunda columna (citas directas), se indica el número de artículos que citan directamente obras de los autores individualizados. En la tercera columna

\footnotetext{
${ }^{17}$ El concepto de género apunta, en general, a que lo masculino y lo femenino no son realidades o hechos naturales, sino construcciones sociales estructurantes a través de las cuales se vertebran múltiples significados y prácticas sociales. GAYLE (1975), p. 159, lo define como el conjunto de arreglos por los cuales una sociedad transforma la sexualidad biológica en productos de la actividad humana, mientras que BENHABIB (1990), p. 125, señala que se trata del modo esencial en que la realidad social se organiza, se divide simbólicamente y se vive empíricamente. Con la expresión perspectiva de género aludimos a la comprensión y evaluación de los significados y dinámicas de poder imbricados en esas relaciones sociales generizadas.

${ }^{18}$ CASAS Y GONZÁLEZ (2012), pp. 250-273.

19 VALENZUELA Y ZÚÑIGA (2014), pp. 119-211; FIGUEROA (2014), pp. 189-214.

${ }^{20}$ MORALES (2016), pp. 10-31.

21 TAPIA (2013), pp. 477-491.

22 IRIARTE (2018), pp. 55-76; JOPIA Y LABBÉ (2018), pp. 437-452; NASH Y NÚÑEZ (2018), pp. 221-270.

${ }^{23}$ FIGUEROA (2012), pp. 117-143; CONTESSE (2012), pp. 155-164; VIAL Y DEL PINO (2015), pp. 261-292; FIGUEROA (2016), pp. 401-433.

${ }^{24}$ SZMULEWICZ (2012), pp. 433-449; COUSO (2012), pp. 193-199.

${ }^{25}$ CAAMAÑO (2003), pp. 25-41.

${ }^{26}$ CAAMAÑO (2009), pp. 175-214; CASAS Y VALENZUELA (2012), pp. 77-101.

${ }_{27}$ MUÑOZ (2013), pp. 373-404.

${ }^{28}$ GONZÁLEZ (2015), pp. 63-106; ZÚÑIGA (2017), pp. 13-25; y VILLAVICENCIO (2018), pp. 43-74.
} 
(artículos totales), se señala el número de textos en donde se cita directamente la obra del autor más la cantidad de citas de artículos que se enfocan en dicho autor analizado por otros autores (citas indirectas).

\begin{tabular}{|l|c|c|}
\hline \multicolumn{1}{|c|}{ Autor } & citas directas & artículos totales \\
\hline Robert Alexy & 39 & 41 \\
\hline Ronald Dworkin & 33 & 35 \\
\hline John Rawls & 28 & 30 \\
\hline Norberto Bobbio & 24 & 24 \\
\hline Luigi Ferrajoli & 23 & 23 \\
\hline
\end{tabular}

De la tabla anterior se desprende que Robert Alexy es el autor más citado, siendo mencionado en 41 artículos, 39 de ellos citando directamente sus obras. En 35 artículos fue citada su publicación "Teoría de los Derechos Fundamentales" ${ }^{29}$, siendo, por tanto, también la obra más citada de toda la muestra.

En segundo lugar, Ronald Dworkin fue citado en 35 artículos, siendo 33 citas directas. De estas 33 citas, 21 corresponden a su obra "Los derechos en serio" ${ }^{30}$.

Luego, John Rawls lidera sus citas directas con su libro "Teoría de la Justicia" 31 (27 de sus 28 citas directas). Por último, "Igualdad y Libertad" 32 de Norberto Bobbio fue citada en 11 oportunidades, mientras que "Derechos y garantías. La ley del más débil" ${ }^{33}$ de Luigi Ferrajoli fue citada en 14 artículos ${ }^{34}$.

b) Doctrina nacional

En cuanto a la doctrina nacional más citada, las tendencias también fueron perceptibles. Los autores constitucionalistas lideran la lista, predominando los libros.

\begin{tabular}{|l|c|}
\hline \multicolumn{1}{|c|}{ Autor } & Número de artículos \\
\hline Humberto Nogueira & 45 \\
\hline José Luis Cea Egaña & 35 \\
\hline Fernando Atria & 31 \\
\hline Miguel Ángel Fernández & 28 \\
\hline Rodolfo Figueroa & 24 \\
\hline Enrique Evans de la Cuadra & 22 \\
\hline
\end{tabular}

Humberto Nogueira es el autor más citado. Sus publicaciones fueron mencionadas en 45 artículos, es decir, fue citado casi en el $20 \%$ del total de la muestra. Las obras citadas fueron diversas, no distinguiéndose una obra principal, sino, por el contrario, ampliándose a variadas publicaciones, entre ellas, su manual "Derecho constitucional" en coautoría con Emilio Pfeffer y Mario Verdugo ${ }^{35}$ (14 citas), el libro "Derechos fundamentales y garantías constitucionales" ${ }^{36}$ (10 citas) y sus artículos "El derecho a la igualdad ante la ley, la no discriminación y acciones positivas" ${ }^{37}$ y "El derecho a la igualdad en la jurisprudencia nacional" ${ }^{38}$, cada uno con 6 citas.

En segundo lugar, encontramos al profesor José Luis Cea Egaña con 35 citas. De ellas, 25 son a su manual "Derecho Constitucional chileno" ${ }^{39}$. Por su parte, Fernando Atria fue citado en

\footnotetext{
${ }^{29}$ Publicado en Centro de Estudios Políticos y Constitucionales, Madrid, España, 1993.

${ }^{30}$ Principalmente, publicada por Editorial Ariel en 1984.

${ }^{31}$ Publicada originalmente en Harvard University Press, 1971.

32 Publicado en Editorial Paidós en 1993.

33 Publicado en Editorial Trotta, Madrid, 1999.

${ }^{34}$ Visualizamos un sesgo hacia la tradición liberal, entendida en sentido amplio. Esto no descarta que autores críticos de la tradición liberal sean utilizados por la doctrina nacional, pero no se encuentran entre los más citados.

${ }^{35}$ Publicado en Editorial Jurídica de Chile, Santiago de Chile, 1994.

${ }^{36}$ Principalmente, publicado en Centro de Estudios Constitucionales, Santiago de Chile, 2008.

37 Publicado en Revista de Derecho Universidad Católica del Norte, Sección Estudios, Año 13 № 2, 2006, pp. 61-100.

38 Publicado en Revista lus et Praxis, Vol. 2 № 2, 1997, pp. 235-259.

39 Publicado en Ediciones Universidad Católica de Chile, Santiago de Chile, la última edición es del año 2019.
} 
31 artículos, de los cuales en 18 oportunidades es citado su libro "Los peligros de la Constitución: la idea de igualdad en la jurisdicción nacional" de $1997^{40}$.

El cuarto autor más citado basa su desarrollo del principio de igualdad en el libro "El principio constitucional de igualdad ante la ley" ${ }^{41}$, en todas sus ediciones. Miguel Ángel Fernández fue citado en 28 artículos y en 22 de ellos, la obra mencionada.

Seguidamente, Rodolfo Figueroa fue citado en 24 oportunidades. Su trabajo más citado es "Igualdad y Discriminación" 42 con 13 referencias. Por último, la obra "Los derechos Constitucionales" ${ }^{43}$ de Enrique Evans de la Cuadra fue citada 19 veces en todos sus tomos, de las 22 referencias que posee.

No podemos dejar de mencionar que la totalidad de los citados son hombres. Esto denota una preocupante observación que nos reveló el análisis de intertextualidad bibliográfica: no solo gran parte de los autores son hombres, sino que hombres y mujeres suelen citar muy mayoritariamente hombres, mientras que casi solo las mujeres citan con frecuencia a otras mujeres.

\subsection{Uso de la jurisprudencia en los artículos de revistas}

La última variable de este estudio considerada es el uso de jurisprudencia. Se clasifican los trabajos según si el autor haya usado o no jurisprudencia, ya sea analizándolas o haciendo alguna referencia a una sentencia en particular. No se distinguió entre categorías de tribunales.

Del total de 235 trabajos, en 167 se mencionó al menos una sentencia judicial. Esto arroja el resultado de que en el $71 \%$ de los textos los autores usan jurisprudencia, ya sea para reforzar sus postulados o para contrastarlos.

Es importante mencionar el uso de jurisprudencia internacional para referirse al principio de igualdad, sobre todo la remisión a fallos del sistema interamericano. La doctrina nacional cita fallos y opiniones consultivas de la Corte, en concordancia con el contenido que dotan los autores a tal principio ${ }^{44}$. Otros tribunales internacionales citados son el Tribunal Europeo de Derechos Humanos ${ }^{45}$ y también se consideran casos emblemáticos de tribunales extranjeros, entre los que destacan fallos de la Corte Suprema de Estados Unidos, el Tribunal Constitucional Español y el Tribunal Supremo Alemán (Bundesgerichtshof, "BGH").

En nuestro país las sentencias más usadas por la doctrina son las del Tribunal Constitucional y las de la Corte Suprema, seguidas de las Cortes de Apelaciones. Ocupan también un lugar menor las sentencias recaídas en acciones de no discriminación arbitraria, conocidas por los Juzgados de Letras ${ }^{46}$.

\section{Algunas hipótesis sobre la producción jurídica en materia de igualdad}

Los datos presentados en la sección anterior nos permiten esbozar algunas hipótesis sobre la productividad chilena relativa al principio de igualdad. La primera hipótesis afirma que es posible describir al menos dos etapas o momentos de la producción académica sobre el principio de igualdad. La primera etapa va desde el año 2000 al año 2009 y la segunda etapa cubre el año 2010 a la fecha. En una primera aproximación exploratoria, planteamos la hipótesis

\footnotetext{
${ }^{40}$ Publicado en Cuadernos de Análisis Jurídico, № 36, Escuela de Derecho, Universidad Diego Portales, 1997.

${ }^{41}$ Publicado en Editorial Jurídica ConoSur, Fundación Fernando Fueyo, Santiago de Chile, 2001 y en Editorial LexisNexis, Santiago de Chile, 2005.

42 Publicado en Cuaderno de Análisis Jurídico, Serie de Publicaciones Especiales de la Universidad Diego Portales, 2001, pp. 9-64

43 Publicado en Editorial Jurídica de Chile, Santiago de Chile, 1994.

${ }^{44}$ A modo ejemplar, ALVEAR (2012), pp. 577-587; CASAS (2013), pp. 398-415; ZÚÑIGA (2015), pp. 440-470; y VALENZUELA (2016), pp. 211-240.

${ }^{45}$ GAUCHÉ (2013), pp. 165-194.

${ }^{46}$ En Chile, el control de constitucionalidad de las normas está entregado al Tribunal Constitucional y a las Cortes. Los demás tribunales no ejercen control de constitucionalidad (no está previsto el control difuso que rige en los Estados Unidos de Norteamérica y Sudáfrica, por ejemplo). Por tanto, no es extraño que, en materia de interpretación del principio constitucional de igualdad, las sentencias más usadas sean las del Tribunal Constitucional y de las Cortes de Apelaciones y Corte Suprema.
} 
de que el hito que marca la diferencia es la discusión y promulgación de la ley antidiscriminación. La segunda hipótesis, complementaria de la anterior, afirma que es posible conectar las etapas de producción académica con el flujo de creación legislativa. Finalmente, las dos hipótesis anteriores nos llevan a inferir que, contra el prejuicio, y al menos en materia de igualdad, la producción jurídica académica es altamente permeable a los debates ciudadanos, aunque genera poco diálogo disciplinar y sus análisis son más bien particulares y no sistemáticos.

\subsection{Panorama doctrinal al ritmo de los cambios legislativos y momentos históricos relevantes}

La doctrina anterior al año 2010, suele utilizar un modelo común del principio de igualdad, enfocado en la igualdad formal y su correlativa prohibición de discriminación arbitraria. Los temas más recurrentes son la igualdad constitucional, el género y las relaciones laborales, así como el análisis parcelado de la igualdad como principio en las distintas ramas del derecho, sobre todo en el derecho civil (principalmente aspectos vinculados al derecho de familia), en el derecho laboral y en el derecho tributario.

Si detallamos cada una de estas ramas, desde el derecho constitucional se evidencia un grueso trabajo sobre la igualdad como cláusula constitucional. A modo puramente ilustrativo, el período empieza con algunos intentos novedosos, como el de Nicolás Espejo, quien advierte "la necesidad de avanzar hacia una conexión más desarrollada de la idea de no-discriminación con ciertas temáticas que se vinculan sustantivamente con el principio de igualdad" ${ }^{47}$. Precisa el autor que esta necesidad se torna imperiosa para el "diseño social de nuestras democracias" 48 . Poco después, desde el reconocimiento del derecho internacional y la Constitución, Zúñiga plantea que la discriminación por edad "hace legítimas las acciones positivas en favor del adulto mayor, bajo la fórmula de discriminación compensatoria o inversa" ${ }^{49}$, introduciendo el análisis de las acciones afirmativas destacadas por la doctrina posterior. Avanzando la década, en el año 2006, Leiva explicita las múltiples voces del principio de igualdad y la exigibilidad de cada una de ellas en nuestro ordenamiento jurídico ${ }^{50}$. Por su parte, Muñoz enfatiza la importancia de los derechos sociales en el marco de una genuina igualdad de oportunidades: "concepto constitucional que determina la actuación de los poderes públicos, de especial aplicación en la formulación de políticas públicas" ${ }^{51}$. Por último, cierra este período Carrasco, quien inaugura una extendida práctica de revisión jurisprudencial del Tribunal Constitucional y sentencias relativas al principio de igualdad ${ }^{52}$.

En el derecho civil, se concretiza el principio de igualdad en instituciones jurídicas históricamente discriminatorias. Un análisis general del principio de igualdad en el derecho sucesorio lo expone Domínguez ${ }^{53}$. En otras áreas del derecho civil, destaca el derecho de familia: la sociedad conyugal, la custodia y el estatuto filiativo son intensas preocupaciones de la doctrina civilista. Lathrop introduce, por ejemplo, la custodia compartida en concordancia con el principio de igualdad entre hombres y mujeres, problematizando la histórica carga maternal que representa para las mujeres la ausencia de responsabilidad paterna. Para la autora es crucial la adopción de "medidas de acción positiva encaminadas a eliminar la discriminación en contra de la mujer" y el reforzamiento de "las políticas de compatibilización de la vida familiar y laboral" ${ }^{54}$. Del mismo modo, tratándose de la filiación, apoyándose en la constitucionalización del derecho de familia, Cornejo analiza "en qué medida el legislador ha dado cumplimiento a los

\footnotetext{
${ }^{47}$ ESPEJO (2000), p. 82.

${ }^{48}$ ESPEJO (2000), p. 107.

49 ZÚÑIGA (2002), p. 239.

${ }^{50}$ LEIVA (2006), pp. 157-172.

${ }^{51}$ MUÑOZ (2007), p. 257.

52 CARRASCO (2008), pp. 215-237.

53 DOMÍNGUEZ (2006), pp. 215-236.

${ }^{54}$ LATHROP (2008), p. 35.
} 
deberes impuestos por la faz estática de los derechos fundamentales de igualdad, identidad e interés superior del niño" 55 .

Luego, desde el derecho laboral, los profesores Gamonal y Caamaño encabezan la lista de autores con mayor desarrollo del principio de igualdad. Gamonal se anticipa, en el año 2003, a lo que ocurrirá años después, resaltando la necesidad de "un avance legislativo no semántico en la materia [laboral], que termine con la impunidad en materia de discriminación" ${ }^{56}$. En la misma línea, Caamaño plantea la exigencia de un estatuto antidiscriminatorio, apoyándose en un examen del sistema jurídico alemán ${ }^{57}$ y la normativa internacional sobre protección de ciertos grupos discriminados, como es el caso de las mujeres. Resulta interesante confirmar que esta primera etapa culmina con un intenso debate legislativo en materia laboral. Así lo indica Caamaño, en el año 2009, al reconocer que "es necesario subrayar como un aspecto positivo el hecho que el legislador laboral en los últimos años ha introducido diversas modificaciones tendientes a perfeccionar las normas protectoras de la maternidad" 58 .

Otra área del derecho con un cierto análisis doctrinal del principio de igualdad es el derecho tributario. Nuevamente, el reconocimiento constitucional de este principio da lugar a múltiples análisis normativos centrados en el alcance del artículo 19 № 20 de la Constitución y sus consecuencias en materia de igualdad, proporcionalidad y justicia tributaria. A juicio de Fernández, de dicho artículo podemos concluir que "quedan excluidas las discriminaciones, pero son admitidas y propiciadas las diferencias justas y razonables" ${ }^{59}$. El análisis también se amplía a la jurisprudencia tributaria, en esa época administrada por el mismo Servicio de Impuestos Internos y su controversial tribunal tributario. Valenzuela, por ejemplo, reflexiona sobre la tensión entre la generalidad de la norma y la particularidad del caso concreto, aplicado a la justicia tributaria ${ }^{60}$.

Si realizamos el análisis a la luz de discusiones legislativas, observamos varias disputas que coparon la coyuntura histórica nacional durante la década pasada y que la doctrina trató profusamente. Entre ellas destacan los múltiples fallos sobre la píldora del día después, la ley de igualdad en las remuneraciones y las primeras discusiones sobre cuotas electorales de género. El fallo del Tribunal Constitucional sobre la píldora del día después es examinado, por ejemplo, por Díaz de Valdés, quien lo califica como "polémico e incómodo" ${ }^{61}$. El académico se detiene, especialmente, en indagar si las diferencias sobre la distribución de la píldora constituirían una discriminación arbitraria.

Retornando al derecho laboral, la Ley № 20.348 de igualdad de remuneraciones publicada en el año 2009, plasmó lo proyectado por la doctrina laboralista años atrás. No obstante, análisis como el de Fábrega y Yáñez dan cuenta de las falencias que dicha regulación pudo causar en las relaciones laborales, advirtiendo que "detrás de una excesiva regulación laboral existe un riesgo inherente a la imposición de obligaciones al empleador" 62 que se manifiesta justamente en el desincentivo para contratar a quienes protege la misma ley: las mujeres. La regulación de tratamientos diferenciados, en virtud del principio de igualdad, trae sus propios dilemas.

Para abordar lo anterior, un paso importante que marca un giro en la discusión en torno al principio de igualdad, fueron las primeras discusiones en torno a la discriminación positiva. Esta arista del principio de igualdad fue mencionada por primera vez durante la década por Rodolfo Figueroa el año 2000, en su artículo "Igualdad y discriminación”. En ese texto, se afirma que la discriminación positiva no es compatible con el principio de igualdad ${ }^{63}$. El año siguiente

\footnotetext{
${ }^{55}$ CORNEJO (2010), p. 43.

56 GAMONAL (2003), p. 104.

${ }^{57}$ CAAMAÑO (2000), pp. 27-40.

58 CAAMAÑO (2009), p. 210.

${ }^{59}$ FERNÁNDEZ (2000), pp. 357-371.

60 VALENZUELA (2001), pp. 2-43.

${ }^{61}$ DÍAZ DE VALDÉS (2008a), pp. 69-121.

62 FÁBREGA Y YÁÑEZ (2009), pp. 697-711.

${ }^{63} \mathrm{El}$ año 2015, Figueroa vuelve sobre el tema. Esta vez señala que la acción afirmativa sí es parte del principio de igualdad entendida como igualdad de resultados y proporciona argumentos para justificar la constitucionalidad de las cuotas como un caso de acción afirmativa. Ver: FIGUEROA (2015), pp. 189-214.
} 
encontramos otro artículo, de Sergio Gamonal, titulado "La lucha contra la discriminación femenina: las acciones positivas y su constitucionalidad" ${ }^{64}$. Años después, Humberto Nogueira desarrolla el tema en su artículo "El derecho a la igualdad ante la ley, no discriminación y acciones positivas" 65, continuando José Manuel Díaz de Valdés en el año 2008 con "Reflexiones previas y necesarias para un análisis jurídico de la discriminación positiva (affirmative action)"66. Estas publicaciones propician un ambiente académico favorable para los futuros debates sobre discriminación positiva, sobre todo en materia de cuotas de género.

A propósito de esto último, si bien recién en el año 2015 se publica la Ley № 20.840 que incorpora cuotas de género en las elecciones parlamentarias, su discusión fue anticipada por la academia. Yanira Zúñiga subraya la importancia de la democracia paritaria como "propuesta de participación equilibrada de mujeres y hombres en los procesos decisorios políticos, para transformarse en un reclamo de vertebración social en un cuadro de responsabilidades compartidas tanto en el ámbito público como en el privado-doméstica" ${ }^{67}$. Por su parte, Alejandra Zúñiga, Daniela Aguilera y Andrea Vásquez reflexionan sobre la baja representación femenina en todas las instituciones y la imperiosa necesidad de contar con una ley de cuotas en Chile ${ }^{68}$.

La muerte de Daniel Zamudio no solo aceleró la promulgación de la ley antidiscriminación, sino que también permitió la visibilización de la comunidad LGTBI+ que, con resquemores, estaba acotada solo a la población homosexual masculina. Las disidencias sexuales encabezan algunas de las polémicas más intensas de la sociedad civil contra ciertos grupos religiosos. El matrimonio homosexual ${ }^{69}$ (y la posterior entrada en vigor del Acuerdo de Unión Civil), la adopción homoparental y la ley de identidad de género, son también temas recurrentes. Sáez asegura, por ejemplo, que "la igualdad requiere que los espacios públicos sean gozados de igual manera por todos los seres humanos; que no haya más lugares y tiempos dominados por la heterosexualidad" 70 . Del mismo modo, el derecho a la identidad de género -luego plasmado en la Ley $N^{\circ} 21.120$ de 2018- requirió de aportes doctrinales para su reglamentación en diversas materias tales como la regulación en los recintos educacionales ${ }^{71}$. Se analizó también su recepción en la jurisprudencia nacional, constitucional ${ }^{72}$ e interamericana, junto con su consagración en diversos instrumentos internacionales ${ }^{73}$.

En el año 2012 se promulgó la Ley №6609 que establece medidas contra la discriminación. La discusión previa a la ley y su entrada en vigor impactaron en el tratamiento del principio de igualdad. No solo aumentaron la cantidad de publicaciones en torno a la fundamentación y contenido de la le ${ }^{74}$, sino que se produce un giro en la configuración de un nuevo marco conceptual asociado a nuevas temáticas como, por ejemplo, el acento en los derechos sociales, en la igualdad material, en las acciones afirmativas y en los grupos en condiciones de vulnerabilidad estructural.

Junto con la ley, nuestro país se enfrenta a un nuevo escenario, producto de la migración y los movimientos sociales, que impactaron en nuevas preocupaciones en la doctrina. La temática de la migración, la educación, la salud, la comunidad LGTBI+, los pueblos indígenas, las políticas multiculturales, la infancia y, otra vez, el género, son algunos de los asuntos relevantes que la doctrina ha seguido en sus investigaciones, a la par del debate contingente.

\footnotetext{
${ }^{64}$ GAMONAL (2001), pp. 69-79.

${ }^{65}$ NOGUEIRA (2006), pp. 61-100.

${ }^{66}$ DÍAZ DE VALDÉS (2008b), pp. 195-243.

67 ZÚÑIGA (2005), p. 132.

68 ZÚÑIGA et al. (2007), pp. 9-30.

${ }^{69}$ El Tribunal Constitucional rechazó un recurso de inaplicabilidad interpuesto en contra de la norma del Código Civil que define el matrimonio como un contrato entre un hombre y una mujer. Por tanto, el tribunal no ha reconocido el matrimonio igualitario. Véase Tribunal Constitucional, Rol №1881-2011, de 3 de noviembre de 2011.

70 SÁEZ (2013), p. 266.

${ }^{71}$ QUEZADA (2017), pp. 261-288.

72 CANALES Y MALLEA (2018), pp. 129-140.

${ }^{73}$ GAUCHÉ (2018), pp. 175-202.

74 ÍÑIGUEZ (2010), pp. 231-242; ALVEAR Y COVARRUBIAS (2012), pp. 9-30; ROSENDE (2012), pp. 31-61; DÍAZ DE VALDÉS (2013), pp. 279297; VIAL (2013), pp. 183-191.
} 
En términos puntuales, se pueden resaltar las discusiones en torno a la educación que el movimiento estudiantil de 2011 elevó como una demanda nacional, generando múltiples discusiones en la doctrina. La implementación de la Ley № 21.091 que consagra la gratuidad en la educación superior no estuvo exenta de críticas. Autores como Díaz de Valdés, argumentaron en su contra, utilizando la jurisprudencia del mismo Tribunal Constitucional que se pronunció sobre la gratuidad a propósito de la ley de presupuestos, al optar por "un test de racionalidad tripartito, el cual exige analizar la relación existente entre la diferencia de trato realizada, los fines que se persiguen con ella y el criterio de diferenciación utilizado"75.

Algo similar ocurrió con el movimiento NO +AFP y las carencias del sistema público de salud, dando lugar a otras tantas publicaciones relativas al sistema previsional y al derecho a la salud. Alejandra Zúñiga confirma la relevancia que suscita el hecho que "las sociedades democráticas modernas obligan a admitir que no es posible garantizar el principio de igualdad equitativa de oportunidades (...) sin que esté asegurado el derecho a cuidado sanitario para todos sus ciudadanos, sin discriminación" ${ }^{\prime 76}$.

Para finalizar el período, el caso "Lonkos" ante la Corte Interamericana de Derechos Humanos, el caso de la pastora Blas, la muerte de comuneros mapuches a manos de funcionarios del Estado, así como la violencia intrafamiliar en contexto indígena, fueron también temas recogidos por la doctrina para extenderse sobre la problemática multicultural. Así, por ejemplo, para Aguirre y Bustos, la utilización preferente de la ley antiterrorista № 18.314 para perseguir personas mapuches contradice los estándares internacionales de derechos humanos ${ }^{77}$. En base a estos mismos estándares, Royo cuestiona la "renuencia de órganos jurisdiccionales chilenos a incorporar las normas del Convenio 169 y demás Tratados internacionales de derechos humanos en causas penales contra imputados indígenas" ${ }^{78}$, cuya principal consecuencia ha sido la condena de tribunales internacionales contra el Estado chileno. En el mismo tono, Villavicencio busca "tender un puente entre las demandas multiculturales y las reivindicaciones feministas para equilibrar las pretensiones diferenciadas de género con una noción de ciudadanía inclusiva" ${ }^{79}$. Por último, es destacable el caso de Lorenza Cahuyán, que para Jopia y Labbé "visibiliza la experiencia de ciertos titulares que, al igual que Lorenza, se caracterizan por tener múltiples identidades $y$, en consecuencia, se encuentran expuestos a la afectación de sus derechos de manera agravada, esto es, a sufrir discriminación múltiple" ${ }^{\prime 80}$. Al término del lapso que cubre esta investigación, la doctrina ha ido enriqueciendo el principio de igualdad con la consolidación de una clase de discriminación multifactorial e interseccional.

\subsection{Fuera de la torre de marfil, pero aislados y poco sistemáticos}

Una cuestión relevante, que fluye del ejercicio realizado, es que los académicos no parecen estar escondidos en ninguna torre de marfil cuando se trata del principio de igualdad. Al contrario, no solo se anticipan a algunas discusiones ciudadanas relevantes, sino que muchas veces reaccionan a las exigencias impuestas por el devenir legislativo y el termómetro público del momento. Esto puede relacionarse con la descripción que Bourdieu (1984) ofrece de las ciencias jurídicas en Homo Academicus. Bourdieu sostiene que, a diferencia de las ciencias puras, la labor académica de las disciplinas integrantes del "polo mundano" (en el que se inscribe las facultades de derecho) no se legitima por una producción de conocimiento totalmente distanciada de la realidad. Su "autoridad científica" se vincula al desarrollo de competencias técnicas combinadas con destrezas técnicas y sociales. Así, las disciplinas jurídicas, por constitución y destinación, están atravesadas por los condicionamientos, expresiones y medios

\footnotetext{
75 DÍAZ DE VALDÉS (2015), p. 258.

76 ZÚÑIGA (2013), p. 337.

77 AGUIRRE Y BUSTOS (2014), pp. 173-201.

${ }^{78}$ ROYO (2015), pp. 362-389.

79 VILLAVICENCIO (2013), p. 110.

80 JOPIA Y LABBÉ (2018), pp. 437-458.
} 
del poder social, lo que explicaría el aumento de la producción de conocimiento vinculada a la discusión legislativa de la igualdad.

A pesar de la profusa producción doctrinal en torno al principio de igualdad, la comunidad jurídica nacional no se lee mucho entre sí. Este dato se ratifica por la poca variedad y desfase temático de los autores chilenos citados. Este hallazgo puede explicarse también en la topografía que ofrece Bourdieu, pese a los indudables cambios introducidos por la profesionalización de la academia en las facultades de derecho. Este observa que en las facultades de derecho no hay "investigadores puros" o teóricos y que las lógicas del trabajo jurídico no responden, entonces, a las lógicas disciplinares de las comunidades vinculadas a las ciencias naturales. En contraste, aparecen subordinadas con mayor frecuencia a comunidades sociales de referencia de las y los académicos y a las ideologías políticas. En un tema tan controversial como la igualdad es previsible entonces que las citaciones sean administradas para amplificar posiciones ideológicas.

Finalmente, y en la misma línea, vemos que la mayoría de los autores que escriben en torno a la igualdad lo hacen para referirse a alguna temática ad-hoc que busca incidir en la doctrina, en el proceso legislativo o en las decisiones judiciales en el marco de alguna teoría de la justicia o una de ideología explícita o implícita. Probablemente la excepción más significativa sea el caso del profesor José Manuel Díaz de Valdés, que es uno de los pocos especialistas en igualdad dentro de la dogmática nacional y que ha abordado esta materia de forma más sistemática y global $^{81}$, aunque es un autor poco citado.

\section{Conclusiones}

A partir de la investigación realizada podemos construir conclusiones cuyo grado de generalización debe ser cuidadosamente estimado. Esta no es una investigación con representatividad estadística que diga relación con toda la producción científica sobre un problema determinado en un tiempo definido. Lo que hemos examinado ha sido aquello que ha sido posible pesquisar mediante una búsqueda bibliográfica. Luego, a partir de ese conjunto hemos compuesto un corpus y una muestra usando criterios cualitativos, pensando en describir, de forma preliminar e inicial, la información recopilada ${ }^{82}$. Esta investigación no debe juzgarse como un análisis bibliográfico del estado del arte de un problema en una disciplina y, por ello, no listamos los especímenes recolectados en el corpus y analizados como muestra dentro de las referencias bibliográficas.

Ahora bien, considerando estas restricciones, pensamos que una investigación como la que hemos desarrollado, puede echar luz sobre aspectos desconocidos del modo en que se producen y consumen textos entro de la comunidad jurídica chilena. A continuación, señalamos algunos de estos aspectos.

1. En cuanto al género de los escritores y escritoras de las publicaciones, observamos que, si bien hay una brecha de género, ésta no es tan severa. Más bien nos acercamos al equilibro de género con un $37 \%$ de autoras y un $63 \%$ de autores. Sin embargo, cuando consideramos los autores más citados, sí podemos observar una brecha de género grave.

2. Visualizamos una concentración de académicos que aglutinan un número importante de publicaciones en torno al principio de igualdad. Específicamente, 8 académicos (correspondiente al 5,09\% del universo) agrupan un cuarto de las publicaciones.

3. Respecto de la importancia y concentración de las fuentes de artículos relativos al principio de igualdad, vemos que éstos se agrupan en no más de 10 revistas jurídicas, dependientes de las universidades más prestigiosas. A su vez, los autores de dichas publicaciones, de igual manera, se agrupan o se relacionan con las mismas universidades.

\footnotetext{
${ }^{81}$ DÍAZ DE VALDÉS (2019).

${ }^{82}$ Es importante recordar que la investigación está orientada por una metodología de teoría fundamentada que permite realizar los pasos de la metodología de forma iterativa y levantar los criterios de selección de los textos a partir de los propios datos recolectados. PARAMO (2015), p. 121.
} 
4. El año de publicación nos permitió cotejar el número y temáticas de las publicaciones según la coyuntura, principalmente asociada a la discusión de proyectos de ley atingentes y los debates públicos más relevantes. Al parecer, los autores desarrollaron el principio de igualdad a la luz de las reformas legislativas y la discusión pública.

5. La doctrina usa profusamente doctrina internacional y nacional. Sobre la doctrina internacional, llama la atención que los autores más citados sean filósofos del derecho o filósofos políticos, relegando a académicos dogmáticos a lugares secundarios. Respecto de la doctrina nacional, ocurre el fenómeno inverso, los autores más citados son dogmáticos. Sobre la jurisprudencia, los autores suelen citar, casi siempre solo con fines ilustrativos jurisprudencia interna, comparada e internacional para enriquecer sus análisis.

6. El análisis de los datos parece mostrar que la productividad académica está influenciada por la tarea legislativa y el debate público en torno a problemas de justicia vinculados con la igualdad. Ello nos permite adelantar algunas hipótesis sobre cómo los dogmáticos entienden su labor. Los propósitos que parecen perseguir los dogmáticos son los siguientes: a) participar o influir en las reformas legislativas; b) influir en las decisiones de los jueces cuando ellos resuelven casos sobre igualdad aplicando nuevas normas legislativas; c) participar del proceso social asociado al ritmo de trabajo del legislador con el fin de entregar herramientas a los litigantes que les permitan construir estrategias para hacer frente a la incertidumbre que genera el cambio legislativo; d) persuadir a sus colegas sobre la idoneidad de sus trabajos para optimizar el material jurídico disponible en el conjunto de fuentes formales del derecho y; e) influir en los miembros de la comunidad normativa que, siendo legos en derecho, tienen liderazgo suficiente para cuestionar el estatus quo del sistema jurídico. Naturalmente, cada una de estas hipótesis es inicial y, además, ellas pueden combinarse entre sí para generar conjeturas más explicativas del fenómeno. Sin embargo, creemos que ellas son un buen punto de partida para tales indagaciones y confirman la multiplicidad de roles que los abogados pueden cumplir en la cultura jurídica.

\section{BIBLIOGRAFÍA CITADA}

AgUiRRE, FEDERICO Y BUStOS, ROdRIGo (2014): “Terrorismo y Constitución de 1980, con especial referencia a la aplicación de la Ley Antiterrorista en el marco del conflicto de Estado con el pueblo mapuche", en: Anuario de Derecho Público UDP (Vol. 5), pp. 173-201.

AleXY, Robert (2014): Teoría de los Derechos Fundamentales (Traducc. Carlos Bernal Pulido, Madrid, Centro de Estudios Políticos y Constitucionales).

AlveAR, Julio (2012): "La sentencia de la CIDH en el caso Atala: una iniciativa para el adoctrinamiento en ideologías radicales", en: Revista de Actualidad Jurídica (№ 26), pp. 577-587.

ALVEAR, JULIO Y COVARRUBIAS, IGNACIO (2012): “Hecha la ley, hecha la trampa: un análisis de los errores de la legislación "antidiscriminación"”, en: Revista de Actualidad Jurídica (Vol. 13, № 26), pp. 9-30.

ARISTÓteles (1941): "Nicomachean Ethics", en: McKeon, Richard, The Basic Works of Aristoteles (Nueva York, Random House), pp. 1094a-1181b.

AtRIA, FERnANDo (2000): “Concepciones de la función judicial: el caso de la igualdad ante la ley”, en: Cuadernos de Análisis Jurídico: Serie de Publicaciones Especiales (Vol. 10), pp. 111-143.

BENHABIB, SEYLA (1990): “El otro generalizado y el otro concreto: la controversia Kohlberg-Gilligan y la teoría feminista", en: Benhabib, Seyla y Cornell, Drucilla (Eds.), Teoría feminista y teoría crítica (Valencia, Alfons el Magnànim), pp. 119-149.

Bourdieu, PIERRE (1984): Homo Academicus (París, Editions de Minuit).

CAAMAÑo, EDUARDo (2000): "El principio de igualdad de trato en el derecho del trabajo", en: Revista de Derecho de Valparaíso (Vol. 21, № 1), pp. 27-40. 
CAAMAÑo, EduARDo (2003): "La tutela del derecho a la no discriminación por razones de sexo durante la vigencia de la relación laboral", en: Revista de Derecho de Valdivia (Vol. 14, № 1), pp. 25-41.

CAAMAÑO, EDUARDO (2009): "Los efectos de la protección a la maternidad para la concreción de la igualdad de trato entre hombres y mujeres en el trabajo", en: Revista de Derecho de Valparaíso (Vol. 33, № 2), pp. 175-214.

CANALES, VAlentina y Mallea, RodRigo (2018): "Estudio de la identidad de género en Chile a la luz de la acción de no discriminación arbitraria (ley 20.609) y el derecho a la identidad", en: Anuario de Derechos Humanos de la Universidad de Chile (Vol. 14), pp. 129-140.

CARRASCO, EDESIO (2008): "Acceso a la justicia, igualdad ante la ley y el término del solve et repete: un valioso cambio en la jurisprudencia del Tribunal Constitucional", en: Sentencias Destacadas (Vol. 5), pp. 215-237.

CASAS, LIDIA (2013): "Los desafíos para Chile de la decisión Artavia Murillo contra Costa Rica de la Corte IDH (Caso fertilización in vitro): algunos comentarios", en: Anuario de Derecho Público UDP (Vol. 4), pp. 398-415.

CASAS, LIDIA y GonZÁleZ, JUAN PABLo (2012): “Estereotipos de género en sentencias del Tribunal Constitucional”, en: Anuario de Derecho Público UDP (Vol. 3), pp. 250-273.

CASAS, LIDIA Y VALENZUELA, ESTER (2012): “Protección a la maternidad: una historia de tensiones entre los derechos de infancia y los derechos de las trabajadoras", en: Revista de Derecho de Valdivia (Vol. 25, № 1), pp. 77-101.

Cisternas, María Soledad (2003): “Ordenamiento jurídico chileno frente al fenómeno discriminatorio", en: Revista Chilena de Derecho (Vol. 31, № 3), pp. 409-437.

CONTESSE, JORGE (2012): "Matrimonio civil y Constitución Política: la sentencia del Tribunal Constitucional sobre matrimonio para parejas del mismo sexo", en: Anuario de Derechos Humanos de la Universidad de Chile (Vol. 8), pp. 155-164.

CoRneJo, PABlo (2010): "Estatuto filiativo y principios constitucionales", en: Revista de Derecho y Humanidades (№ 16, Vol. 2), pp. 44-61.

COUSO, JAIME (2012): “Acerca de la pertinencia de la nueva ley de no discriminación para combatir la estigmatización de los homosexuales en Chile", en: Revista de Derecho Público Iberoamericano (№ 1), pp. 193-199.

CRuz, JuAn Antonio (2006): "Los métodos para los juristas", en: Courtis, Christian (Ed.), Observar la ley. Ensayos sobre metodología de la investigación jurídica (Madrid, Trotta), pp. 17-39.

Díaz De VALdÉs, José MANuel (2008a): “La píldora del día después: principales aspectos de un fallo polémico e incómodo", en: Sentencias destacadas (Vol. 5), pp. 69-121.

Díaz De VALdÉs, José MANuel (2008b): “Reflexiones previas y necesarias para un análisis jurídico de la discriminación positiva (affirmative action)", en: Revista de Actualidad Jurídica (Vol. 9, № 17), pp. 195-243.

Díaz De Valdés, José Manuel (2013): “¿Es la ley Zamudio verdaderamente una ley general antidiscriminación?", en: Revista de Actualidad Jurídica (Vol. 14, № 28), pp. 279-297.

Díaz De Valdés, José Manuel (2015): “La gratuidad discriminatoria”, en: Sentencias destacadas (Vol. 12), pp. 235-261.

Díaz De VALdÉs, José MANUel (2019): Igualdad constitucional y no discriminación (Valencia, Tirant lo Blanch).

Domínguez, RAmón (2006): "Principios en el derecho sucesorio en el Código de Bello y su estado actual", en: Revista de Derecho de la Universidad de Concepción (№ 219-220), pp. 215-236. 
DWORKIN, RONALD (1981a): "What is Equality? Part 1: Equality of Welfare", en: Philosophy \& Public Affairs (Vol. 10, № 3), pp. 185-246.

DWORKIN, RONALD (1981b): "What is Equality? Part 2: Equality of Resources", en: Philosophy \& Public Affairs (Vol. 10, № 4), pp. 283-345.

ESPEJO, NICOLÁs (2000): "La garantía de no discriminación y el principio de igualdad", en: Cuadernos de Análisis Jurídico. Serie de Publicaciones Especiales (Vol. 10), pp. 65-109.

FÁBREGA, HUGo y YÁÑEZ, DoRA (2009): "Breve análisis crítico sobre la ley de igualdad en las remuneraciones", en: Revista de Actualidad Jurídica (Vol. 10, № 20), pp. 697-710.

FernÁndez, Miguel Ángel (2000): “Principios constitucionales de proporcionalidad y justicia en materia tributaria", en: Revista Chilena de Derecho (Vol. 27, № 2), pp. 357-371.

FigueroA, ROdolfo (2000): "Igualdad y discriminación”, en: Cuadernos de análisis jurídico de la Universidad Diego Portales, Serie Publicaciones Especiales (№ 10), pp. 9-64.

FigUeROA, RODOlFo (2012): “El matrimonio ante el Tribunal Constitucional”, en: Anuario de Derecho Público UDP (Vol. 3), pp. 117-143.

FigueroA, Rodolfo (2015): “¿Son constitucionales las cuotas de género para el Parlamento?”, en: Revista Chilena de Derecho (Vol. 42, № 1), pp. 189-214.

FIGUEROA, RODOLFo (2016): “Acción afirmativa en la jurisprudencia del Tribunal Constitucional”, en: Revista Chilena de Derecho (Vol. 43, № 2), pp. 401-433.

GLASER, BARNEY (1992): Basics of grounded theory analysis (Mill Valley, CA: Sociology Press).

GAMONAL, SERGIO (2001): “La lucha contra la discriminación femenina: las acciones positivas y su constitucionalidad", en: Revista Laboral Chilena (№ 8), pp. 69-79.

GAMONAL, SERGIO (2003): "El principio de no discriminación por razones de sexo en materia laboral”, en: Cuadernos Jurídicos Universidad Adolfo Ibáñez (№ 8), pp. 83-105.

García, Cecilia y Agüero, Claudio (2014): “Bases para el estudio de la dinámica discursiva en la comunidad jurídica chilena", en: Revista de Derecho (Vol. XXVII, № 1), pp. 59-79.

GAUCHÉ, XIMENA (2013): “La orientación sexual como categoría sospechosa de discriminación y su tratamiento por el Tribunal Europeo de Derechos Humanos", en: Revista de Derecho de la Universidad de Concepción (№ 233-234), pp. 165-194.

GAuCHÉ, XIMENA (2018): “Comentarios a la OC 24/17 de la Corte IDH en materia de identidad de género", en: Anuario de Derecho Público UDP (Vol. 9), pp. 175-202.

GONZÁlEZ, JUAN ANDRÉs (2015): “¿Es el derecho a la educación un derecho justiciable?”, en: Revista de Derecho Público Iberoamericano (№ 6), pp. 63-106.

GUASTINI, RICCARDO (2013): “Breve lección sobre la igualdad”, en: Eunomía (№ 4), pp. 33-41.

ÍNIIGUEZ, ANDREA (2010): “Notas y comentarios sobre proyecto de ley que establece medidas contra la discriminación", en: Revista Ars Boni et Aequi (Vol. 6, № 1), pp. 231-242.

IRIARTE, CLAUDIA (2018): "La discriminación estructural de género y su recepción sistémica en el sistema de derechos humanos", en: Anuario de Derechos Humanos (Vol. 14), pp. 55-76.

Jopia, VALENTINA Y LABBÉ, NATALIA (2018): “Discriminaciones múltiples y la recepción en el derecho interno: el caso de Lorenza Cahuyán”, en: Estudios Constitucionales (Vol. 16, № 1), pp. 437-452.

LATHROP, FABIOLA (2008): "Algunas consideraciones en torno a la custodia compartida de hijos", en: Revista Chilena de Derecho Privado (№ 10), pp. 9-37. 
LEIVA, FelIPE (2006): "Los límites de la igualdad como derecho fundamental o lo que le podemos exigir a la Constitución sin ser defraudados", en: Revista de Derecho y Humanidades (№ 12), pp. 157-172.

Morales, VAlentina (2016): “Hacia una nueva y más igualitaria sociedad conyugal”, en: Revista Estudios Jurídicos. Democracia y Justicia (№ 5), pp. 10-31.

MUÑOZ, FERNANDO (2007): "Principios rectores del orden social e igualdad de oportunidades", en: Anuario de Derecho Constitucional Latinoamericano (Tomo II, Año 13), pp. 243-257.

MUÑOZ, FERNANDO (2013): “Ciudadanía laboral: crítica y defensa de un concepto jurídico-político", en: Revista de Derecho Universidad Católica del Norte (Vol. 20, № 2). pp. 373-404.

NASH, CLAUdio y NúÑEZ, CONSTANZA (2018): "Impacto del Derecho Internacional de los DDHH en la protección jurisdiccional de grupos en situación de discriminación estructural en Chile", en: Estudios Constitucionales (Vol. 16, № 2), pp. 221-270.

Nogueira, Humberto (2002): "El derecho a la igualdad ante la ley, no discriminación y acciones positivas", en: Revista de Derecho Universidad Católica del Norte (Vol. 13, № 2), pp. 61-100.

PÁRAMO, DAGOBERTO (2015): “La teoría fundamentada (Grounded Theory), metodología cualitativa de investigación científica”, en: Pensamiento y gestión (№ 39), pp. 1-7.

PÉREZ-LUÑo, ANTONIO (1981): "El concepto de igualdad como fundamento de los derechos económicos, sociales y culturales", en: Anuario de Derechos Humanos de la Universidad Complutense de Madrid (№ 1), pp. 257-275.

Quezada, Flavio (2017): “Protección jurídica de la identidad de género en los establecimientos educacionales", en: Revista Derecho y Crítica Social (Vol. 3, № 2), pp. 261-288.

RoJAS, MARIO (2001): “¿igualdad jurídica en Chile?”, en: Revista de Actualidad Jurídica (Vol. 2, № 4), pp. 199-208.

ROSENDE, HUGO (2012): "La pugna valórica en la ley que establece medidas contra la discriminación arbitraria", en: Revista de Actualidad Jurídica (Vol. 13, № 26), pp. 31-61.

Royo, MANUela (2015): "Derecho Penal e interculturalidad como manifestación del principio de igualdad", en: Revista de Política Criminal (Vol. 10, № 19), pp. 362-389.

RUBIN, GAYLE (1975): "The Traffic in Women: Notes on the "Political Economic" of Sex", en: Reiter, Raina (Ed.), Toward an Anthropology of Women (NY-London, Monthly Review Press), pp. 33-65.

SÁEZ, MACARENA (2013): "Igualdad y orientación sexual”, en: Revista de Derecho y Humanidades (№ 21), pp. 259-270.

SeN, AmARTYA (1995): Inequality Reexamined (Cambridge, Harvard University Press).

Squella, Agustín; Villavicencio, Luis y ZúÑIGA, Alejandra (2012): Curso de filosofía del derecho (Santiago, Editorial Jurídica de Chile).

STRAUSS, ANSELM Y CORBIN, JULIET (1998): Basics of qualitative research: techniques and procedures for developing grounded theory (Thousand Oaks, CA: Sage).

SZMULEWICZ, ESTEBAN (2012): "Igualdad, orientación sexual y juicio estricto de proporcionalidad. Comentario a la sentencia de la CIDH en el caso Atala Riffo", en: Revista de Derecho Universidad Católica del Norte (Vol. 19, № 1), pp. 433-449.

TAPIA, MAURICIO (2013): "Comentarios críticos a la reforma del cuidado personal de los hijos (Ley 20.680)", en: Revista Chilena de Derecho Privado (№ 21), pp. 477-491.

TORRUELLA, JOAN Y LLISTERRI, JOAQUIM (1999): "Diseño de corpus textuales y orales", en: Blecua, José Manuel; Clavería, Gloria; Sánchez, Carlos y Torruela, Joan (Eds.), Filolofía e informática. 
Nuevas tecnologías en los estudios filológicos (Barcelona, Departamento de Filología Española, Universidad Autónoma de Barcelona, Editorial Milenio), pp. 45-77.

TRABucco, Alia (2005): “Género, derecho y sistema política, un desafío pendiente", en: Revista de Derecho y Humanidades (№ 11), pp. 349-363.

Valenzuela, Cecilia y Zúñiga, Alejandra (2014): "Leyes de cuota electorales, Constitución y democracia", en: Revista de Derecho de la Universidad Austral (Vol. 27, № 1), pp. 119-211.

VAlenzUela, Mylene (2016): "Niños y niñas indígenas en la jurisprudencia de la Corte Interamericana de Derechos Humanos", en: Revista de Derecho Universidad Católica del Norte (Vol. 23, № 2), pp. 211-240.

VAlenzuela, RodRigo (2001): “Justicia tributaria en Chile”, en: Revista de Derecho Económico (№ 73), pp. 2-43.

VIAL, TOMÁs (2013): "La nueva Ley Antidiscriminación: propuestas para avanzar en su perfeccionamiento", en: Anuario de Derechos Humanos de la Universidad de Chile (Vol. 9), pp. 183-191.

VIAL, TOMÁs Y DEL PINO, SEBASTIÁN (2015): "El Tribunal Constitucional y la homosexualidad: análisis de las sentencias roles 2435 y 2681, a la luz de su jurisprudencia anterior sobre discriminación por orientación sexual", en: Anuario de Derecho Público UDP (Vol. 6), pp. 261-292.

VILLAVICENCIO, LUIS (2013): “Ciudadanía para las mujeres, diversidad cultural y jurisdicciones multiculturales", en: Revista de Derecho y Humanidades (№ 22), pp. 107-121.

VILLAVICENCIO, LUIS (2018): "Justicia social y principio de igualdad", en: Revista de Filosofía HYBRIS (Vol. 9), pp. 43-74.

ZúNIGA, ALEJANDRA (2013): "La teoría distributiva de Dworkin y el derecho a la protección de la salud", en: Revista de Derecho Universidad Católica del Norte (Vol. 20, № 1), pp. 323- 338.

ZÚÑIGA, ALEJANDRA (2017): "Él ingreso básico universal como nuevo derecho social”, en: Revista de Ciencias Sociales (Vol. 70), pp. 13-25.

Zúñiga, Alejandra; Aguilera, Daniela Y Vásquez, Andrea (2007): "Lejos del poder. Hacia la implementación de una ley de cuotas en Chile", en: Revista de Derecho de la Universidad Austral (Vol. 20, № 2), pp. 9-30.

ZÚNIIGA, FRANCISCO (2002): "Principio de no discriminación, principio de discriminación compensatoria e igualdad constitucional", en: Anuario de Filosofía Jurídica y Social (№ 20), pp. 237-260.

ZúNIIGA, Francisco (2015), "Comentario a la sentencia "Personas dominicanas y haitianas expulsadas vs. República Dominicana" de la Corte IDH", en: Anuario de Derecho Público UDP (Vol. 6), pp. 440-470.

ZúÑIGA, YANIRA (2005): "Democracia paritaria: de la teoría a la práctica", en: Revista de Derecho de la Universidad Austral (Vol. 18, № 2), pp. 131-154. 